\title{
Frequency based signal processing technique for pulse modulation ground penetrating radar system
}

\author{
Che Ku Nor Azie Hailma Che Ku Melor ${ }^{1}$, Ariffuddin Joret ${ }^{2}$, Maryanti Razali ${ }^{3}$, Asmarashid Ponniran ${ }^{4}$, \\ Muhammad Suhaimi Sulong ${ }^{5}$, Rosli Omar ${ }^{6}$ \\ 1,2,3,4,6 Faculty of Electrical and Electronic Engineering, Universiti Tun Hussein Onn Malaysia, Malaysia \\ ${ }^{2,5}$ Faculty of Technical and Vocational Education, Universiti Tun Hussein Onn Malaysia, Malaysia \\ 2,3,5 Internet of Things (IOT) Focus Group, Universiti Tun Hussein Onn Malaysia, Malaysia \\ ${ }^{4}$ Power Electronic Converters (PECs) Focus Group, Universiti Tun Hussein Onn Malaysia, Malaysia
}

\begin{abstract}
Article Info
ABSTRACT

Article history:

Received Sep 1, 2020

Revised Mar 21, 2021

Accepted Apr 3, 2021

\section{Keywords:}

Dipole antenna

Fast fourier transform

magnitude

Ground penetrating radar

Phase

Pulse modulation GPR

This paper discusses the method of processing the pulse modulation (PM) ground penetrating radar (GPR) system to detect an embedded object underground. The proposed technique is using frequency domain operation which can be classified based on two parameters which are magnitude and phase. The process of detecting the position and depth of iron objects in dry sandy soil is easier to identify using the techniques and parameters that have been introduced. The selection of the Dipole antenna as a sensor device to detect iron objects has been designed in a frequency range of $70 \mathrm{MHz}$ to 80 MHz. Based on the simulation, the proposed technique seems to be able to detect underground iron objects. By using the magnitude value, the underground iron object that can be detected as displayed in GPR radargram is in the depth range from $0 \mathrm{~mm}$ until $1000 \mathrm{~mm}$. Meanwhile, by using the phase value, the embedded underground iron object detected is in the range of depth between $900 \mathrm{~mm}$ and $1000 \mathrm{~mm}$. Therefore, based on this promising result, the proposed technique and parameters are considered to be used in the signal processing system of the PM GPR to detect an embedded object.
\end{abstract}

This is an open access article under the CC BY-SA license.

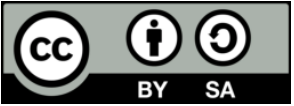

\section{Corresponding Author:}

Ariffuddin Joret

Faculty of Electrical and Electronic Engineering

Universiti Tun Hussein Onn Malaysia (UTHM)

86400 Parit Raja, Johor, Malaysia

Email: ariff@uthm.edu.my

\section{INTRODUCTION}

Ground penetrating radar (GPR) is used in detection or locating an embedded object underground [1]-[3]. The system uses the application of electromagnetic waves propagation characteristics in locating and estimating underground objects [4]. Time domain, frequency domain and spatial domain are referring to the category of operating domain in the GPR system [3]. However, based on this operating domain, there are only two types of operation domain always applied in the GPR system, time and frequency. In general, the operating system of GPR in the time domain uses techniques of amplitude modulation such as pulse modulation (PM). Whereas, the GPR system operating in the frequency domain always uses the stepped frequency continuous wave (SFCW) technique [5], [6]. Moreover, these types of GPR system had gotten a lot of attention from researchers because the system involves only one-dimensional data processing which makes it easier to be processed compared to the operating system of GPR in the spatial domain [7]-[9].

Referring to the PM GPR system, there are two types of signals involved which are information signal and carrier signal. The difference between the information signal and the carrier signal is that the 
information signal has a low-frequency signal using the sinusoidal type while the carrier signal has a highfrequency signal using Gaussian pulse signal [9]-[11]. In contrast, the SFCW GPR system uses only one type of signal that is sinusoidal with variable frequency values. The signal processing technique of this system is usually done in the frequency domain where the receiving signal of the GPR system will be converted from the time domain using the fast fourier transform (FFT) algorithm [12]-[15]. Basically, a GPR system contains a transmitter/receiver system and antenna, as shown in Figure 1. Based on Figure 1, the pulse generator acts as a transmitter system while the Oscilloscope acts as the receiver system.

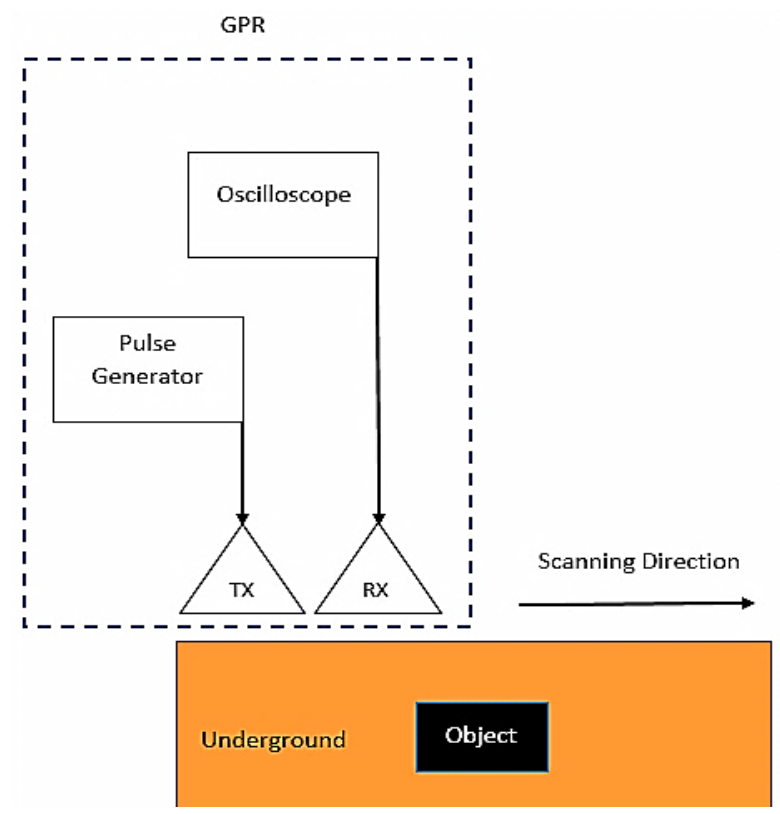

Figure 1. Block diagram of GPR system

As the PM GPR system typically operated in the time domain, this study will propose the development of the signal processing technique of the system in the frequency domain [16]-[18]. The proposed system simulation model of PM GPR is performed using CST microwave software studio while signal processing of the system will be done using MATLAB software. Analysis of the PM GPR system performance operated in the frequency domain will be done based on the GPR radargram produced.

\section{PM GPR SYSTEM SIMULATION DEVELOPMENT}

The design of the dipole antenna with operating frequency from $70 \mathrm{MHz}$ until $80 \mathrm{MHz}$, having cooper material in developing PM GPR system simulation using call setup time (CST) software is as shown in Figure 2 [11]. Referring to the SFCW GPR system, receiving signal of the system needs to be transformed from the time domain into the frequency domain by using the discrete fourier transform (DFT) technique. The signal transformation of the discrete frequency domain $\mathrm{S}(\mathrm{k})$ is based on (1):

$$
S(k)=\sum_{n=0}^{N-1} s(n) e^{-j 2 \pi n k / N}, \mathrm{k}=1,2,3, \ldots \mathrm{N}-1
$$

Based on (1), $n$ is sample value while $N$ is sample number, thus the calculation of the transformation required $N^{2}$ multiplication. Computationally efficient algorithms to compute the DFT using only $N \log _{2} N$ multiplication can be done using fast fourier transform (FFT). The algorithm is considered a computational efficiency algorithm which has an ability to produce high accuracy in signal levels [19]-[21]. As the FFT analysis is a Fourier transform that converts signals from the time domain to the frequency domain [22]-[24], based on this algorithm, the important value of the signal in time will be stored, and exponent components will be calculated repeatedly to complete the history of time [25], [26]. The transformation signal calculated using this algorithm can be classified into two parameters which are magnitude and phase calculation.

The dipole antenna design and its parameters can be referred to Figure 2 and Table 1 respectively. Figure 3 shows an overview of the GPR system simulation is setup consists of a Dipole antenna on the top of 
the model size of the ground object was made as rectangular form using dry sandy soil material with a diameter of $3000 \mathrm{~mm}$ Length, $3000 \mathrm{~mm}$ Width and $2000 \mathrm{~mm}$ height. Meanwhile, an iron bar with a diameter of $800 \mathrm{~mm}$ Length, $800 \mathrm{~mm}$ width and $400 \mathrm{~mm}$ height was buried inside a ground object. The detailed information on the PM GPR system simulation model design in CST software and its scanning methods can be referred to the paper [11].

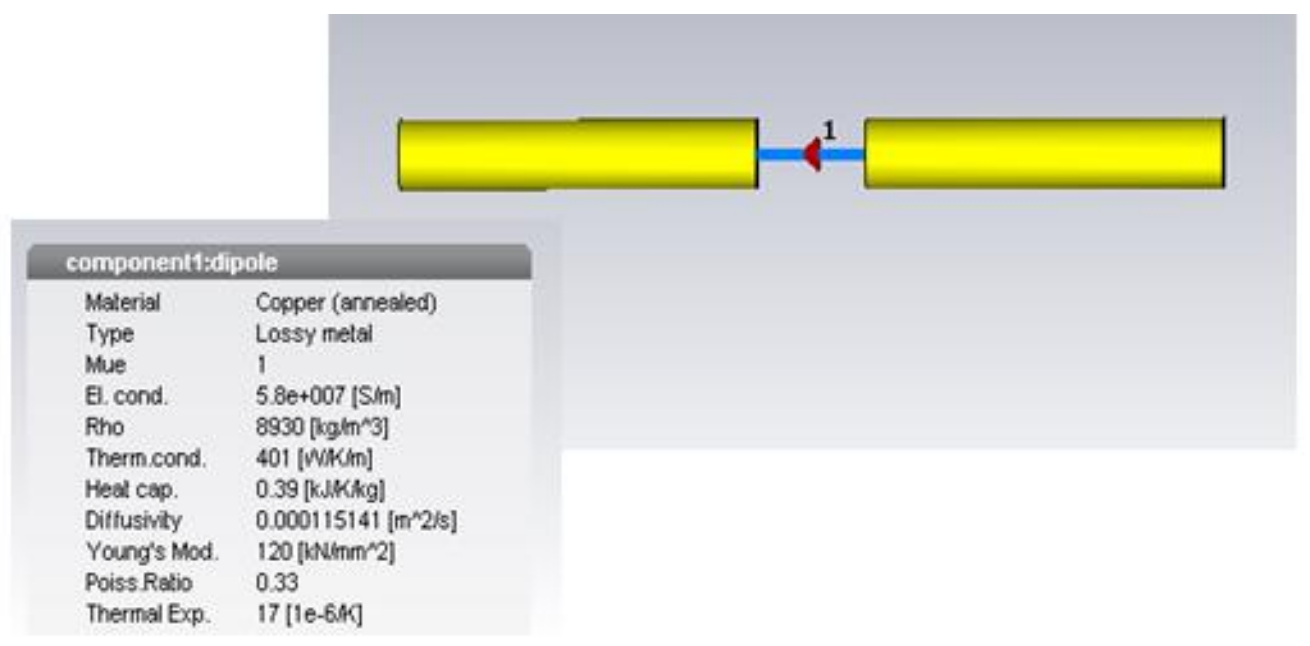

Figure 2. Dipole antenna design in CST [11]

Table 1. Design parameter of dipole antenna

\begin{tabular}{ccc}
\hline Parameter & Value & Unit \\
\hline Operating Frequency & $70-80$ & $\mathrm{MHz}$ \\
Length of Dipole (L) & 1500 & $\mathrm{~mm}$ \\
Radius of the Dipole (R) & 50 & $\mathrm{~mm}$ \\
Gap (G) & 200 & $\mathrm{~mm}$ \\
\hline
\end{tabular}

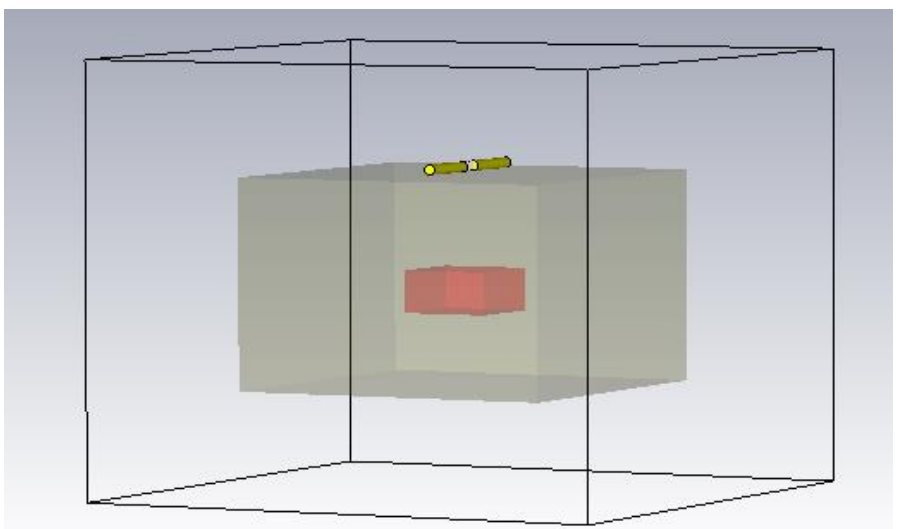

Figure 3. GPR system simulation model using CST software [11]

\subsection{Signal processing of PM GPR system based on fast fourier transform (FFT)}

The proposed signal processing technique applied in this study using the FFT algorithm consists of two calculation values which are magnitude and phase. Based on the value of this calculation, the GPR radargram is produced. The processing algorithm in the proposed technique will need a reference input signal. This signal is actually an input signal of the simulation system of the GPR developed in this study. As for the real application, this input signal as a reference signal for the algorithm can be achieved from the signal generator of the transmitter system which will be used to feed the transmitter antenna. 


\subsection{Signal processing technique for PM GPR system based on magnitude of FFT calculation}

Figure 4 represents the flow chart of the signal processing algorithm of the PM GPR system based on the magnitude calculation in the frequency domain using the FFT technique. Referring to this flowchart, the algorithm starts by uploading input and output signals obtained from the PM GPR system simulation in CST software into MATLAB software. After that, the signal readings in the time domain will be converted into the frequency domain using the FFT method. Next, the ratio of the magnitude values from the FFT transformation between output and input signals is calculated. The construction of the PM GPR radargram is done by arranging this calculated value in the form of a matrix referring to the column of each scanning position in the simulation system.

\subsection{Signal processing technique for PM GPR system based on phase of FFT calculation}

The simplified flow chart for PM GPR radargram based on the phase of FFT calculation as depicted in Figure 5. Based on the flow chart, the phase difference of the FFT calculation between the output and the input signals is calculated to track the reflections in the presence of an embedded object in the radargram image of the proposed PM GPR system. Comparing this flow chart with the flow chart of Figure 4, the difference is as can be seen in the third block where this flow chart uses phase value while Figure 4 uses magnitude value.

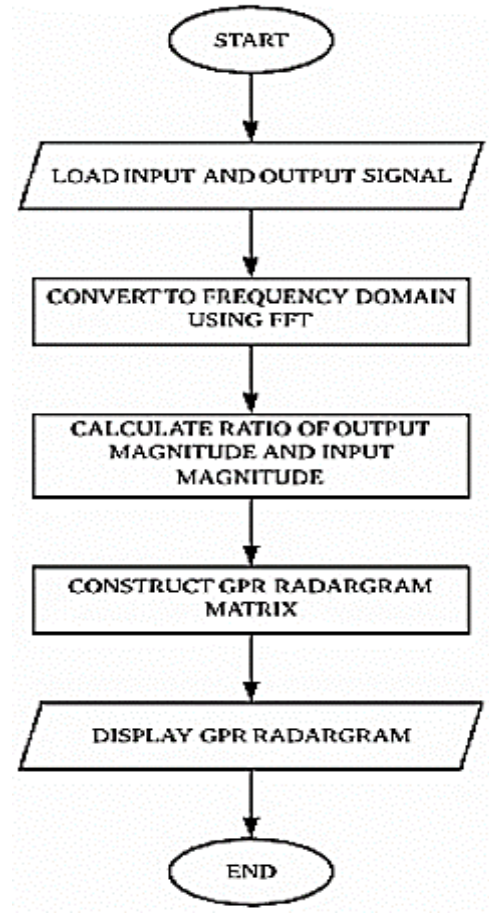

Figure 4. Flow chart for PM GPR radargram based on magnitude of FFT calculation

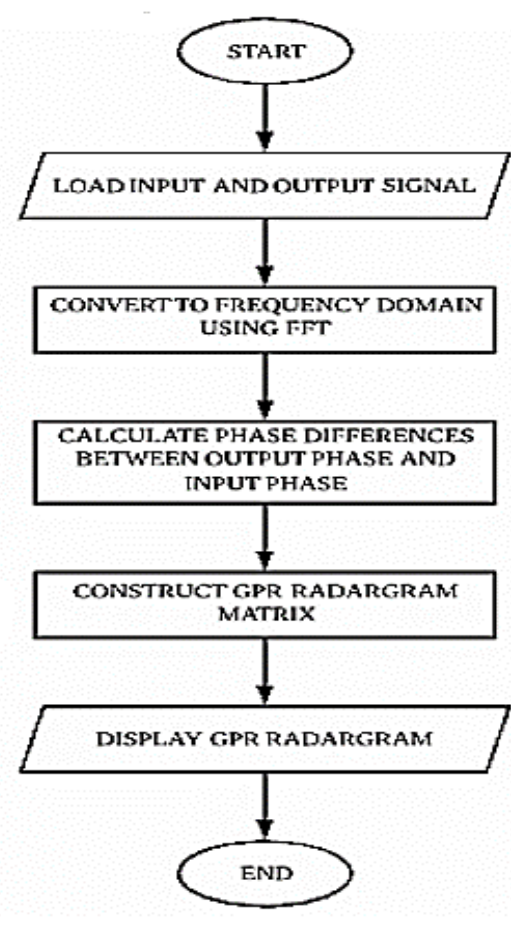

Figure 5. Flow chart for PM GPR radargram based on phase of FFT calculation

\section{RESULT AND DISCUSSION}

\subsection{Simulation result based on magnitude of FFT calculation}

The analysis of the PM GPR system based on the magnitude of FFT calculation capabilities developed in this study is based on the image of the GPR radargram generated using MATLAB software. In this study, simulation of PM GPR system in scanning sandy soil area contains the buried object of iron at depths of $10 \mathrm{~mm}, 100 \mathrm{~mm}, 500 \mathrm{~mm}, 900 \mathrm{~mm}$ and $1000 \mathrm{~mm}$ was made. As for the reference to assist interpretation in this study, the simulation of the PM GPR system without the buried object of iron has also been created. Referring to Figure 6(a) to Figure $6(\mathrm{~g})$, the image of the GPR radargram generated from the propose PM GPR system based on the magnitude value, the buried object of the iron was detected at positions between 1 and 11 of frequency samples in all simulations. Referring to the scanning position, the object can be estimated to embed at the scanning position of 8 until 10. However, referring to the radargram pattern, the correct depth position of the embedded object cannot be clearly estimated. 


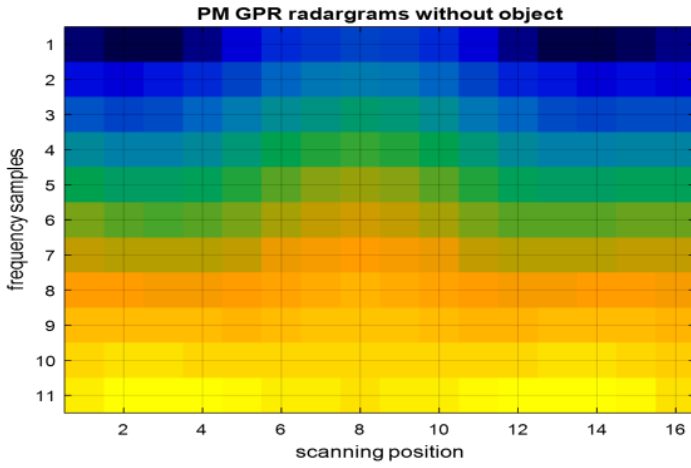

(a)

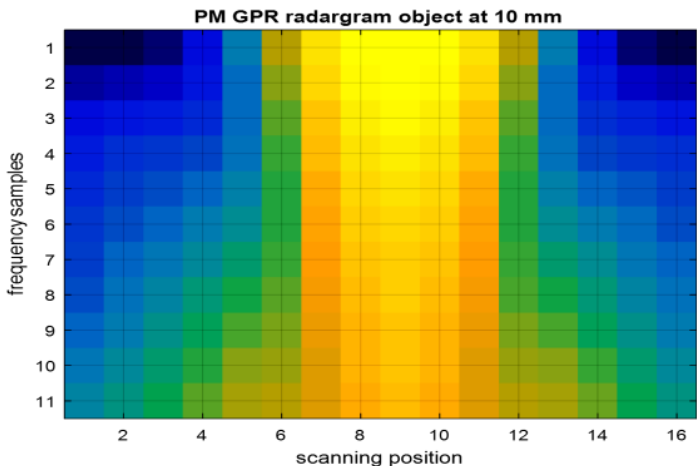

(c)

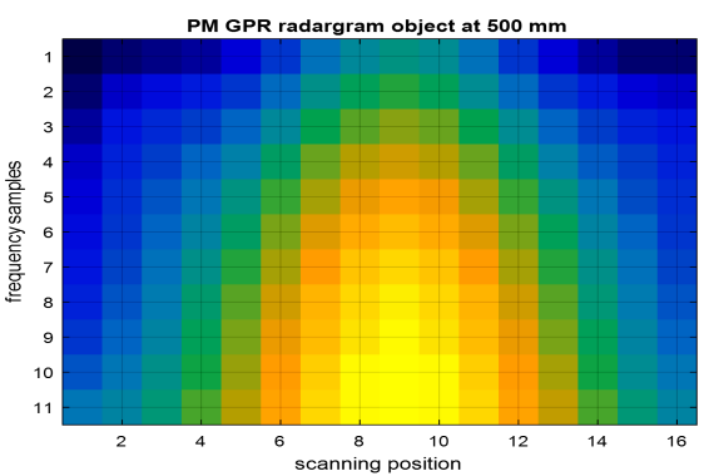

(e)

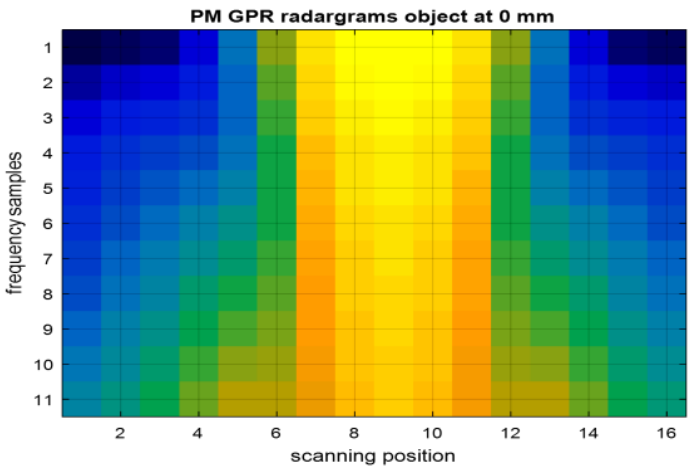

(b)

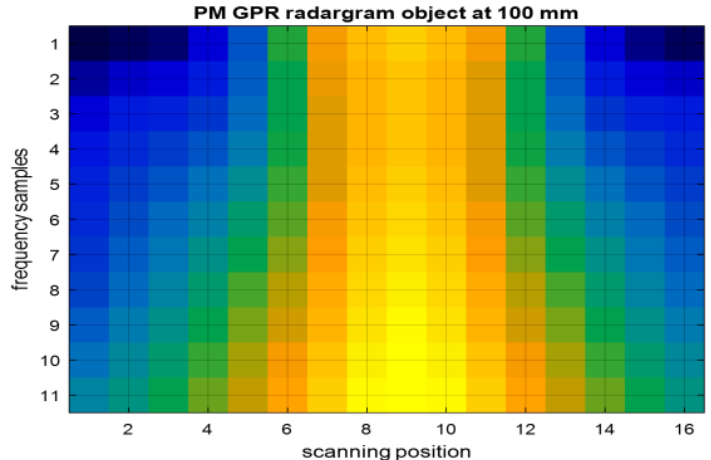

(d)

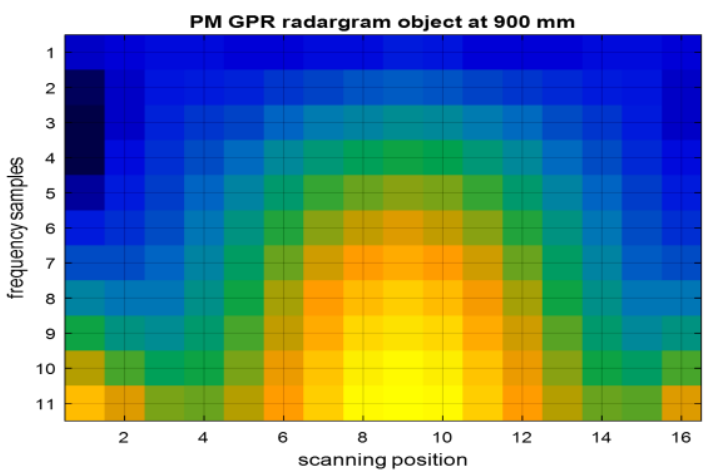

(f)

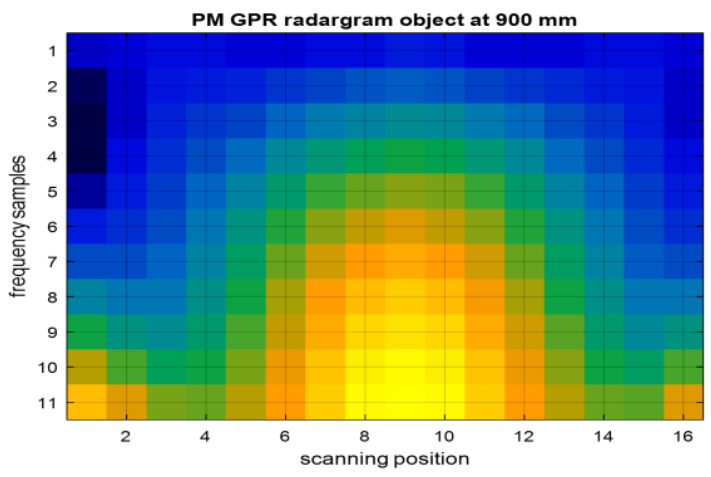

(g)

Figure 6. Results after PM GPR radargram processed based on magnitude of FFT calculation; (a) without a buried object of iron, (b) with a buried object of iron at a depth of $0 \mathrm{~mm}$, (c) with a buried object of iron at a depth of $10 \mathrm{~mm}$, (d) with a buried object of iron at a depth of $100 \mathrm{~mm}$, (e) with a buried object of iron at a depth of $500 \mathrm{~mm}$, (f) with a buried object of iron at a depth of $900 \mathrm{~mm}$, (g) with a buried object of iron at a depth of $1000 \mathrm{~mm}$ 
Referring to the colour pattern of these GPR radargrams, the simulation without embedded iron object in Figure 6(a) seems to have a spreading yellow color at all scanning positions. On the other hand, the spreading of yellow color in the GPR radargram of Figure 6(b) to Figure 6(g) seems to spread on the scanning position of 5 to 11 . This indicator can be used to interpret that there is an embedded iron object in these Figures. As referring to the frequency samples in the GPR radargrams, the spreading of yellow color in the image has been reduced as the position of the embedded iron object in the simulation increases. This indicator could be further analysed in order to correctly estimate the depth position of the embedded iron object in the simulation.

\subsection{Simulation result based on phase of FFT calculation}

The image of the GPR radargram generated from the PM GPR system simulation processed using phase values of FFT calculation can be seen in Figure 7(a) to Figure 7(g). The position of the iron object only can be estimated at the depth of $900 \mathrm{~mm}$ and $1000 \mathrm{~mm}$. This is referring to the color pattern of the GPR radargram produced. Referring to the yellow color in the radargram of Figure 7(a), the spreading is at a scanning position of 4 until 12. The orange color in this figure seems to have some correlation with the yellow color which can be assumed as some part of the underground which does not contain any embedded object.

Based on Figure 7(b) until Figure 7(e), the spreading of yellow color is almost the same which is at the scanning position of 3 until 15. The spreading pattern of the yellow color is quite wide which seems almost same as the spreading of the yellow color in Figure 7(a). In contrast, the yellow color spreading in Figure 7(f) and Figure 7(g) seems to focus on the scanning position from 6 until 12 and from 7 until 11 respectively. This can be used as an indicator to estimate the embedded iron object. Based on these figures, the depth of the iron object in the PM GPR radargram is said to have been embedded at frequency samples of 4 and 5. The object seems to appear at a scanning position of 8 until 10.

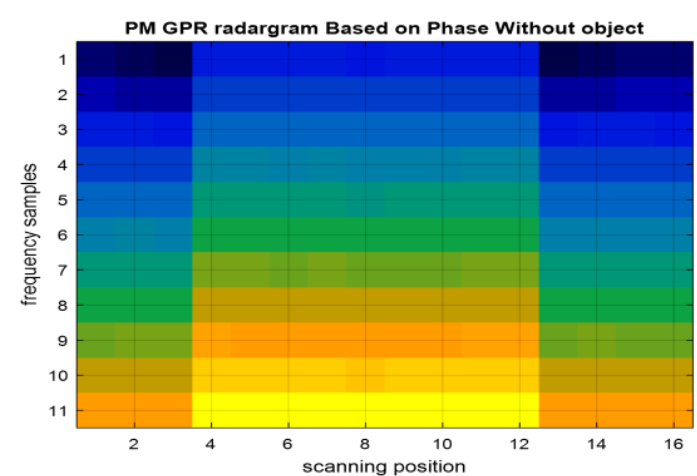

(a)

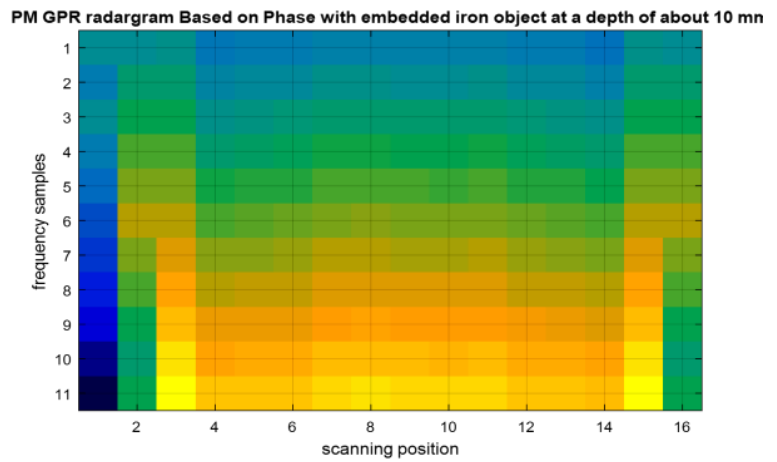

(c)

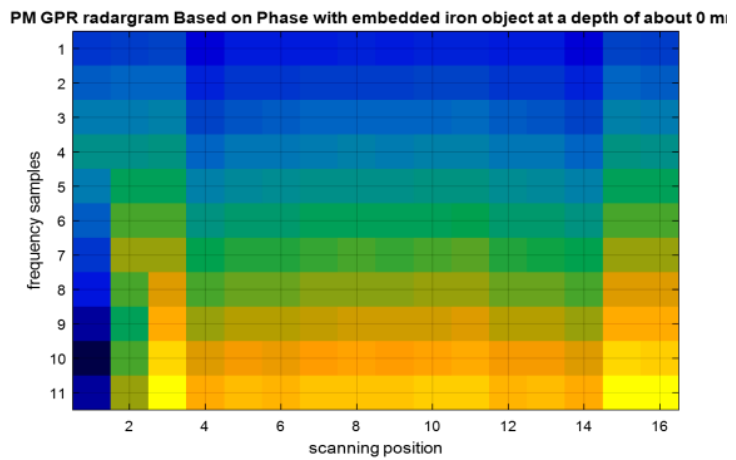

(b)

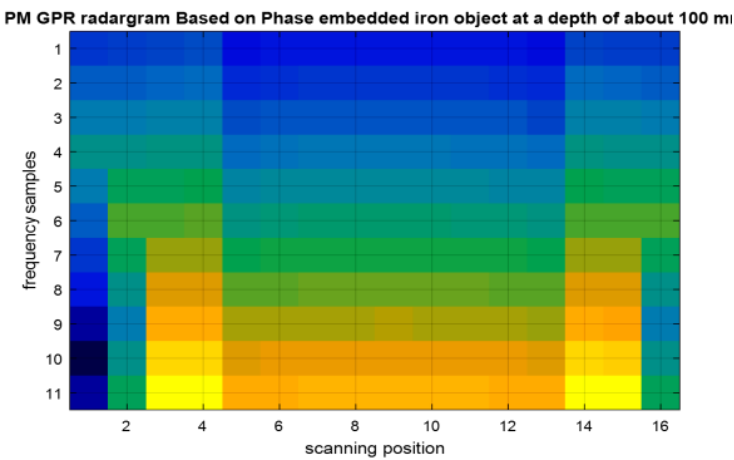

(d)

Figure 7. Results after PM GPR radargram processed based on phase of FFT calculation: (a) without a buried object of iron; (b) with a buried object of iron at a depth of $0 \mathrm{~mm}$; (c) with a buried object of iron at a depth of $10 \mathrm{~mm}$; (d) with a buried object of iron at a depth of $100 \mathrm{~mm}$; (e) with a buried object of iron at a depth of $500 \mathrm{~mm}$; (f) with a buried object of iron at a depth of $900 \mathrm{~mm} ;(\mathrm{g})$ with a buried object of iron at a depth of $1000 \mathrm{~mm}$ (continue) 


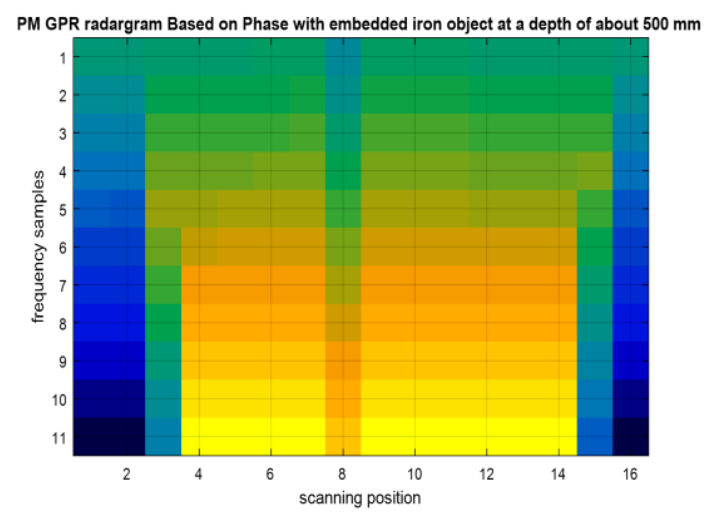

(e)



(f)

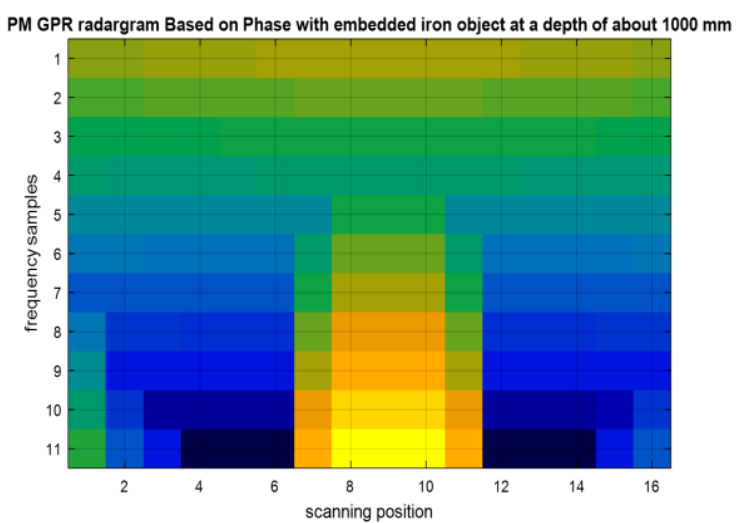

(g)

Figure 7. Results after PM GPR radargram processed based on phase of FFT calculation: (a) without a buried object of iron; (b) with a buried object of iron at a depth of $0 \mathrm{~mm}$; (c) with a buried object of iron at a depth of $10 \mathrm{~mm}$; (d) with a buried object of iron at a depth of $100 \mathrm{~mm}$; (e) with a buried object of iron at a depth of $500 \mathrm{~mm}$; (f) with a buried object of iron at a depth of $900 \mathrm{~mm} ;(\mathrm{g})$ with a buried object of iron at a depth of $1000 \mathrm{~mm}$

\section{CONCLUSION}

The system of PM GPR has been developed and simulated using signal processing techniques in the frequency domain successfully. From the images of the GPR radargram that has been generated, the position of the embedded iron object in the simulation has been successfully detected for all depths using the magnitude of FFT calculation. However, by using the phase of FFT calculation the embedded iron object can only be detected at a depth of $900 \mathrm{~mm}$ and $1000 \mathrm{~mm}$. The position of the embedded object can also be predicted correctly based on the scanning position. The estimated of the embedded object position based on depth need to be further studied especially using the magnitude of the FFT calculation technique. As this study is focusing on the iron object, in order to enhance the capabilities of the signal processing techniques developed, the PM GPR system simulation can be designed using other materials as ground and embedded objects.

\section{ACKNOWLEDGEMENTS}

The author wishes to acknowledge Pejabat Penerbitan Universiti Tun Hussein Onn Malaysia and the Government of Malaysia for technical and financial support in this research.

\section{REFERENCES}

[1] D. J. Daniels, "Ground Penetrating Radar," London, the Institution of Engineering and Technology, 2004.

[2] C. Science and H. G. Poley, "GPR Antennas Design and Experimental Evaluation," 2010. [Online]. Available: https://repository.tudelft.nl/islandora/search/?type=dismax\&collection=heritage 
[3] K. M, Chew, R. Sudirman, N. H. Mahmood, N. Seman, and C. Y. Yong, "Human Brain Microwave Imaging Signal Processing: Frequency Domain (S-parameters) to Time Domain Conversion," Scientific Research, Engineering, vol. 5, no. 5, pp. 31-36, 2013, doi: 10.4236/eng.2013.55B007.

[4] S. Karamzadeh and C. Eren, "Optimal Signal Processing Methods in GPR," International Journal of Electronics Mechanical and Mechatronics Engineering, vol. 3, no. 3, pp. 585-589, 2013.

[5] S. M. Screstha and I. Arai, "Signal Processing of Ground Penetrating Radar Using Spectral Transformation Techniques to Estimate the Position of Buried Targets," EURASIP Journal on Applied Signal Processing, vol. 12, pp. 1198-1209, 2003, doi: 10.1155/S1110865703307036.

[6] A. Joret, "Modulation Techniques for Gpr System Radargram Ariffuddin Bin Joret Universiti Tun Hussein Onn Malaysia," Modulation Techniques for GPR System Radagram, 2018.

[7] M. Nishimoto, D. Yoshida, K. Ogata, and M. Tanabe, "Target response extraction from measured GPR data," 2012 International Symposium on Antennas and Propagation (ISAP), Nagoya, Japan, 2012, pp. 427-430.

[8] W. Shao, A. Bouzerdoum, and S. L. Phung, "Sparse Representation of GPR Traces with Application to Signal Classification," in IEEE Transactions on Geoscience and Remote Sensing, vol. 51, no. 7, pp. 3922-3930, July 2013, doi: 10.1109/TGRS.2012.2228660.

[9] L. Qiao, Y. Qin, X. Ren, and Q. Wang, "Identification of Buried Objects in GPR using Amplitude Modulated Signals Extracted from Multiresolution Monogenic Signal Analysis," Sensors (Switzerland), vol. 15, no. 12, pp. 30340-30350, 2015, doi: 10.3390/s151229801.

[10] Joret, M. S. Sulong, M. F. L. Abdullah, A. Madun, and S. H. Dahlan, "Design and Simulation of Horn Antenna Using CST Software for GPR System,” in Journal of Physics: Conference Series, vol. 995, no. 1, pp. 1-15, 2018, doi: 10.1088/1742-6596/995/1/012080/meta.

[11] C. K. N. A. H. C. K. Melor., A. Joret, A. Ponniran, M. S. Sulong, R. Omar, and M. Razali, "Signal processing technique for pulse modulation (pm) ground penetrating radar (gpr) system based on phase and envelope detector technique," Proceedings of the 11th National Technical Seminar on Unmanned System Technology 2019, vol. 666, pp. 659-669, 2019, doi: 10.1007/978-981-15-5281-6_46.

[12] C. M. Furse, S. P. Mathur, and O. P. Gandhi, "Improvements to the finite-difference time-domain method for calculating the radar cross section of a perfectly conducting target," in IEEE Transactions on Microwave Theory and Techniques, vol. 38, no. 7, pp. 919-927, Jul. 1990, doi: 10.1109/22.55785.

[13] C. A. Balanis, "Antenna Theory: Analysis and Design,” Antenna theory: analysis and design, vol. 3, pp. 811-882, 2005.

[14] C. S. Burrus, "Fast Fourier Transform," Rice University, Houston, Texas, 2012.

[15] A. B. Suksmono, E. Bharata, A. A. Lestari, A. G. Yarovoy and L. P. Ligthart, "Compressive Stepped-Frequency Continuous-Wave Ground-Penetrating Radar," in IEEE Geoscience and Remote Sensing Letters, vol. 7, no. 4, pp. 665-669, Oct. 2010, doi: 10.1109/LGRS.2010.2045340.

[16] J. L, Cai, C. M, Tong, W. J, Zhong, and W. J, Ji, "3D Imaging Method for Stepped Frequency Ground Penetrating Radar Based on Compressive Sensing," Progress in Electromagnetics Research M, vol. 23, pp. 153-165, 2012, doi:10.2528/PIERM11121206.

[17] I. Catapano, G. Gennarelli, G. Ludeno, F. Soldovieri, and R. Persico, "Ground-Penetrating Radar: Operation Principle and Data Processing," in Wiley Encyclopedia of Electrical and Electronics Engineering, pp. 1-23, 2019, doi: 10.1002/047134608X.W8383

[18] S. U. Rehman and M. A. S. Alkanhal, "Time to Frequency Domain Analysis of Narrow Band Antennas," International Journal of Antennas and Propagation, vol. 2017, 2017, doi: 10.1155/2017/7419179.

[19] M. Richards, "Time and Frequency Domain Windowing OF LFM Pulses," pp. 1-7, 2006.

[20] A. A. Ahmad, A. S. Saliu, A. E. Airoboman, U. M. Mahmud, and S. L. Abdullahi, "Identification of Radar Signals Based on Time-Frequency Agility using Short-Time Fourier Transform," Journal of Advances in Science and Engineering, vol. 1, no. 2, pp. 1-8, 2018.

[21] A. A. Ahmad, M. Ajiya, Z. Y. Yusuf, and A. E. Airoboman, "On the identification of low probability of intercept radar signals using time-frequency signal analysis and processing," Journal of Electrical and Electronics Engineering, vol. 12, no. 2, pp. 5-10, 2019.

[22] N. J. Cassidy, "Ground penetrating radar data processing, modelling and analysis." Ground penetrating radar: theory and applications, pp. 141-176, 2009.

[23] A. M. Mohamed Mostapha, G. Alsharahi, and A. Driouach, "2D FDTD Simulation of Ground Penetrating Radar Imaging Under Subsurface with Two Different Antenna Types,” Procedia Manufacturing, vol. 22, pp. 420-427, 2018, doi: 10.1016/j.promfg.2018.03.066.

[24] C. Warren, L. Pajewski, D. Poljak, A. Ventura, A. Giannopoulos and S. Sesnic, "A comparison of finite-difference, finite-integration, and integral-equation methods in the time-domain for modelling ground penetrating radar antennas," 2016 16th International Conference on Ground Penetrating Radar (GPR), Hong Kong, China, 2016, pp. 1-5, doi: 10.1109/ICGPR.2016.7572676.

[25] P. T. W. Wong, W. W. L. Lai and M. Sato, "Time-frequency spectral analysis of step frequency continuous wave and impulse ground penetrating radar," 2016 16th International Conference on Ground Penetrating Radar (GPR), Hong Kong, China, 2016, pp. 1-6, doi: 10.1109/ICGPR.2016.7572694.

[26] M. Nishimoto and D. Yoshida, "Signal processing for extraction of target response from distorted GPR data," 2013 International Symposium on Electromagnetic Theory, Hiroshima, Japan, 2013, pp. 1109-1112. 


\section{BIOGRAPHIES OF AUTHORS}
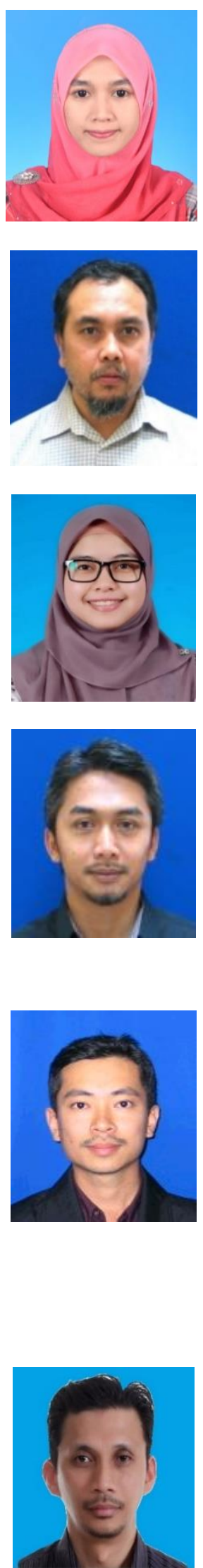

Che Ku Nor Azie Hailma Che Ku Melor is a PhD Scholar in Faculty of Electrical and Electronics Engineering, Universiti Tun Hussein Onn Malaysia (UTHM). She received her Master degree from Universiti Tun Hussein Onn Malaysia in 2012. Currently She joined Radio Communications and Antenna Design (RACAD) laboratory, where she is working to complete her PhD at Universiti Tun Hussein Onn Malaysia. Her current research interests including antenna design, antenna for Ground Penetrating Radar applications and signal processing.

Ariffuddin Joret is a senior lecturer in Faculty of Electrical and Electronics Engineering, Universiti Tun Hussein Onn Malaysia (UTHM). He received his first degree in electrical and electronic engineering from Universiti Teknologi MARA (UiTM) in 2000. In 2006, he recived his Master of Science (Electrical and Electronics Engineering) in Neural Network from Universiti Sains Malaysia (USM). He completed his phD in 2018 in signal processing field from Universiti Tun Hussein Onn Malaysia (UTHM). His current research interests including Ground Penetrating Radar, Radar and Internet of Things (IoT) system development including application.

Maryanti Razali is a postgraduate student from Electrical and Electronics Engineering Faculty (FKEE), Universiti Tun Hussein Onn Malaysia (UTHM). She graduated from UTHM with major in Electronics Engineering for her undergraduate study. Due to the passion in research world, she pursued her study on 2019 at the same university. Her current research interest is image and signal processing of Ground Penetrating Radar (GPR) and antenna design for GPR applications. In a way of finishing her Master Degree, she joins Radio and Communication and Antenna Design (RACAD) Laboratory under Dr. Ariffuddin Joret supervision.

Asmarashid Ponniran received the Bachelor of Electrical Engineering degree from Universiti Tun Hussein Onn Malaysia (UTHM), Malaysia, in 2002 and the degree of Master of Engineering (Electrical Power) from Universiti Teknologi Malaysia, Malaysia, in 2005. Then, he received the Doctor of Engineering $(\mathrm{PhD})$ degree in Energy and Environment Science from Nagaoka University of Technology, Japan, in 2016. He is currently an associate professor at UTHM. His research interests in power electronics area including power converter's circuit structure optimization, switching strategies for modular multilevel power converters, high power density achievement of power converters, high-voltage-gain power converters and high-frequency power converters. These research interests are toward renewable energy (RE), electric vehicle (EV), smart grid power system (SGPS) and data centre of power system (DCPS) applications.

Muhammad Suhaimi Sulong is a Senior Lecturer and Head of Technology Programme at Faculty of Technical and Vocational Education, Universiti Tun Hussein Onn Malaysia (UTHM). $\mathrm{He}$ is a joint founder of Microelectronics and Nanotechnology-Shamsuddin Research Centre (MiNT-SRC) UTHM established in November 2006 and joining a focus group research in IoT Technology Unit. He had experienced joining the Nano Research Group in the School of Electronics and Computer Science, University of Southampton, UK (2003-2004) and also as Visiting Scholar at University of South Australia (2011-2012). He received his Doctorate in Higher Education from Universiti Selangor (UNISEL), Malaysia in 2017, M.Sc. Microelectronics from Universiti Kebangsaan Malaysia (UKM) in 2005, and B.Eng. (Hons) Electrical Engineering (Computer Engineering) from UTHM in 2002. His current research interests are IC design, IoT-based research, training and skill, curriculum development, internationalization of higher education, and e-learning. Currently he holds a position as Head of Department (Lifelong Learning), Institute of Ahli Sunnah Wal Jamaah, UTHM.

Rosli Omar is currently an associate professor at Faculty of Electrical and Electronic Engineering, Universiti Tun Hussein Onn Malaysia (UTHM). He received his $\mathrm{PhD}$ in engineering from University of Leicester, United Kingdom in 2012. His first degree was accomplished in 1999 in instrumentation and control engineering. He then pursued his master's degree in electrical engineering, specialised in system identification and graduated in 2002. Both his first dan master's degrees are from Universiti Teknologi Malaysia (UTM). His research interests are in robotic engineering, autonomous system and system identification. 